\title{
Factors associated with survival in the herd for dairy cows following surgery to correct left displaced abomasum
}

\author{
Jennifer L. Reynen, David F. Kelton, Stephen J. LeBlanc, Nathalie C. Newby, and Todd F. Duffield ${ }^{1}$ \\ Department of Population Medicine, University of Guelph, Guelph, Ontario N1G 2W1, Canada
}

\begin{abstract}
Left displaced abomasum (LDA) is a common problem in dairy cows. There have been numerous studies focused on predicting prognosis for right displaced abomasal corrective surgery, but a paucity of studies exist focused on more common LDA surgeries. Our objective was to determine if survival to $60 \mathrm{~d}$ or 1 yr after surgery could be predicted from the physical exam findings, periparturient disease status, and a biochemical profile from a blood sample obtained at the time of LDA diagnosis. Blood $\beta$-hydroxybutyrate (BHBA) concentrations were measured immediately using a hand-held meter. Data obtained from CanWest DHI (Guelph, ON, Canada) for all of the study subjects ( $\mathrm{n}=179$ cases, by 24 veterinarians from 4 clinics), including cull date, cull reason, and test-day milk production. Cows were classified based on whether or not they were culled within 60 $\mathrm{d}$ or $1 \mathrm{yr}$ of surgery. Based on logistic regression, cows that had dystocia [odds ratio $(\mathrm{OR})=13,95 \%$ confidence interval $(\mathrm{CI})=7-26]$ or were not ketotic (blood BHBA $<1.2 \mathrm{mmol} / \mathrm{L} ;$ OR $=3,95 \% \mathrm{CI}=1.03-9)$ at the time of corrective surgery were more likely to be culled within $60 \mathrm{~d}$. Higher serum concentrations of BHBA $(\mathrm{OR}=0.95,95 \% \mathrm{CI}=0.92-0.98)$, nonesterified fatty acids $(\mathrm{OR}=0.81,95 \% \mathrm{CI}=0.75-0.88)$, and $\mathrm{Mg}$ $(\mathrm{OR}=0.49,95 \% \mathrm{CI}=0.35-0.68)$ all had a protective effect against culling within 1 yr of LDA surgery. Based on survival analysis, longevity in the herd for $365 \mathrm{~d}$ following corrective surgery was associated with higher BHBA and $\mathrm{Mg}$ at the time of LDA diagnosis before surgery, as well as milk production following surgery.
\end{abstract}

Key words: dairy cow, displaced abomasum, prognosis, $\beta$-hydroxybutyrate

\section{INTRODUCTION}

The lactational incidence risk of displaced abomasum, in particular left displaced abomasum (LDA), appears to be slowly increasing over time (Geishauser et al.,

Received October 25, 2014

Accepted March 12, 2015.

${ }^{1}$ Corresponding author: tduffiel@uoguelph.ca
1998; LeBlanc et al., 2005; Newby et al., 2013). Recent literature reported the LDA incidence rate between 3 and $7 \%$ of calvings in North America (Gröhn et al., 1998; LeBlanc et al., 2005; Chapinal et al., 2011). Of these cases, 12 to $17 \%$ are reported as having a negative outcome, defined as culling or death within $30 \mathrm{~d}$ after corrective surgery (Boulay et al., 2014). With a high rate of negative outcomes and increasing incidence, it is increasingly important to predict the likelihood of a successful recovery for surgical candidates.

Numerous studies have focused on predicting the prognosis for right displaced abomasum (RDA). Figueiredo et al. (2006) found that increasing $\mathrm{Cl}$ and lactate serum concentrations and heart rate were accurate predictors of RDA outcomes $30 \mathrm{~d}$ following surgical correction. Boulay et al. (2014) demonstrated similar findings with increasing plasma lactate levels and the indication for negative outcomes at RDA diagnosis. However, the majority of abomasal displacements are diagnosed on the left side (Shaver, 1997).

An important risk factor for the development of LDA is ketosis; subclinical ketosis is typically defined as blood BHBA levels $\geq 1.2 \mathrm{mmol} / \mathrm{L}$ in the absence of clinical signs (Suthar et al., 2013). Croushore et al. (2013) reported that cows with serum BHBA below 1.2 $\mathrm{mmol} / \mathrm{L}$ at the time of surgical correction were at 2.5 (95\% CI $=1.3-5.0)$ times greater risk of being culled within $30 \mathrm{~d}$; cows that had ketosis were more likely to recover and remain in the herd than those who were not ketotic (Croushore et al., 2013).

Numerous studies have shown that elevated concentrations of indicators of aspects of liver function, such as aspartate aminotransferase, glutamate dehydrogenase, ornithine carbamoyl transferase, BHBA, NEFA, and bilirubin have all been associated with an increased risk of culling or death (Kalaitzakis et al., 2006; Stengärde et al., 2010; Maden et al., 2012). Serum electrolyte levels have also been shown to have some prognostic ability: decreased $\mathrm{Ca}$ and $\mathrm{Mg}$ were associated with an increased risk of poor outcomes in cows with LDA (Kalaitzakis et al. 2010), whereas increased concentrations of $\mathrm{Na}$ and $\mathrm{Cl}$ were associated with a positive prognosis following surgery (Rohn et al., 2004). Increased risk of culling up to 60 DIM and increased LDA risk have been as- 
sociated with serum BHBA $\geq 1.2 \mathrm{mmol} / \mathrm{L}, \mathrm{NEFA} \geq 0.8$ $\mathrm{mmol} / \mathrm{L}$, and $\mathrm{Ca} \leq 2.2 \mathrm{mmol} / \mathrm{L}$ (LeBlanc et al., 2005; Roberts et al., 2012).

Despite a growing body of knowledge of the risk factors associated with an LDA, little research has been done regarding postsurgical prognosis for LDA. Most studies considered only a few perisurgical factors for up to 2 mo after surgery. Our objective was to determine factors associated with dairy cows remaining in the herd following LDA corrective surgery based on concurrent disease status, physical examination findings, and blood biochemistry profiles at the time of diagnosis of uncomplicated LDA.

\section{MATERIALS AND METHODS}

The data were obtained in a randomized clinical trial that investigated the effects of ketoprofen on physiological, behavioral, and production parameters in Holstein dairy cows following LDA corrective surgery (Newby et al., 2013). Ketoprofen had no effect on culling, physiological, behavioral, or production outcomes measured.

\section{Data Collection}

The cows were enrolled from May 2009 through November 2009 through 4 veterinary practices located within $100 \mathrm{~km}$ of Guelph, Ontario, Canada. Cows were enrolled following the diagnosis of a LDA and then underwent surgical correction using 1 of 3 surgical techniques: right paralumbar fossa omentopexy (RF), left paralumbar fossa abomasopexy $(\mathbf{L F})$, or right paramedian abomasopexy $(\mathbf{P})$. The specific details of the trial, including surgical procedures and anesthetic protocols can be found in Newby et al. (2013).

At the time of diagnosis, all cows received a routine physical examination measuring heart rate (beats per minute), respiration rate (breaths per minute), temperature $\left({ }^{\circ} \mathrm{C}\right)$, dehydration score $(0=$ none, 1 $=$ mild, $2=$ moderate, $3=$ severe $)$, rumen motility (contractions per minute), and strength $(0=$ none, 1 = poor, $2=$ moderate, $3=$ strong). Blood BHBA was measured using a hand-held ketometer (Precision Xtra; Abbott Laboratories Ltd., Saint-Laurent, QC, Canada) with a blood sample from the coccygeal vessels. A behavioral assessment was also conducted using a simple ethogram [for full details refer to Newby et al. (2013)]: BAR = bright, alert, and responsive, QAR = quiet, alert, and responsive, $\mathrm{D}=$ dull or depressed, and $\mathrm{NR}=$ nonresponsive. Information regarding the cow's periparturient disease status, calving date, parity, physical examination findings, surgical and anesthetic technique, as well as general farm management practices were obtained at the time of enrollment.
Disease definitions were from Kelton et al. (1998). Blood samples for serum harvest were also taken before surgery from the coccygeal vessels using an evacuated sterile tube without anticoagulant (Vacutainer, Becton Dickinson, Franklin Lakes, NJ). The samples were allowed $1 \mathrm{~h}$ to clot and then centrifuged at 7,000 $\times g$ (International Clinical Centrifuge, model CL, International Equipment Co., Needham Heights, MA) and the serum separated. Serum samples were then stored at $-20^{\circ} \mathrm{C}$ until submission to Animal Health Laboratory at the University of Guelph for serum biochemistry analysis (Ca, P, Mg, Na, K, Cl, total protein, albumin, globulin, urea, glucose, $\gamma$-glutamyl transferase, aspartate aminotransferase, glutamate dehydrogenase, BHBA, NEFA, and haptoglobin).

\section{Follow-Up}

Cull dates and reasons for culling recorded up to January 1, 2014 (4 yr after the last case was enrolled), were obtained for all cows. Data were received from the official milk-recording database maintained by CanWest DHI (Guelph, ON, Canada) and from records maintained by the participating veterinary clinics. Any cows that had a missing cull date and were not still in the milking herd were excluded from all analyses. Cows still milking in their respective herd were censored for statistical analysis as of January 1, 2014. Milk production and reproductive data for the lactation in which LDA correction occurred were also obtained from CanWest DHI.

The year of graduation of the veterinarian who performed the LDA correction surgery was obtained from the College of Veterinarians of Ontario to classify practitioners as more or less clinically experienced to determine if clinical experience had an effect on surgery outcome. An experienced veterinarian was defined as having spent 5 or more years in clinical practice and a less experienced veterinarian was one with less than 5 yr of practice experience at the time of the study.

\section{Statistical Analysis}

All descriptive and statistical analyses were performed using SAS 9.4 (SAS Institute Inc., Cary, NC). In all analyses, clustering by veterinary clinic was accounted for using a random effect. This also indirectly controlled for surgical procedure, as each clinic had a preferred technique for LDA correction.

All variables were screened for inclusion in the multivariable models based on univariable associations with the outcome of interest (culled in $60 \mathrm{~d}$ or $1 \mathrm{yr}$ of surgery) and using a $P$-value $<0.10$. All continuous variables that met the $P$-value were then assessed for 
collinearity. If 2 variables were highly correlated (i.e., had a Pearson correlation coefficient $>|0.80|$ ) then the variable with the fewest missing observations was retained in the model-building process.

Forward stepwise model building strategies were used for the final multivariable models using PROC GLIMMIX for logistic regression models and Kaplan-Meier (LIFETEST procedure) and Cox proportional hazards regression (PHREG procedure) for the survival analysis. At this stage statistical significance was based on a $P$-value $\leq 0.05$. The variable with the smallest $P$-value in univariable analyses was first added into the model, followed by the variable with the next smallest $P$-value and so forth. If at any stage any variable became not statistically significant, it was removed from the model until all remaining variables had a $P$-value $\leq 0.05$.

A survival analysis using the same forward stepwise model-building strategies as previously mentioned was conducted to determine time to culling over $1 \mathrm{yr}$ following the LDA surgery. The end points were based on whether the cow remained in the herd or had been culled. Because calving is a high-risk period for cows, if a subsequent calving date was available it was used as a censor point. For cows that had not yet been culled or did not have a subsequent calving within $365 \mathrm{~d}$, a censor date was set $365 \mathrm{~d}$ from the date of surgery. Milk production (M24 rank: the percentile rank of the 24-h milk yield of the cow within the herd on the first CanWest DHI test following her LDA corrective surgery) was included in the model as a likely confounder. After all models had been built, residual analyses were preformed including assessing outliers and model fit.

\section{RESULTS}

\section{Study Population}

Of the 179 cows enrolled, 3 were excluded due to incomplete follow-up data. Overall, 176 Holstein cows were enrolled from 112 different farms in 4 different veterinary practices. A total of 17 cows were still present in the milking herd. Prior to any statistical analyses and censoring, the median survival time for the entire study population was $566 \mathrm{~d}$ (18.9 mo).

\section{Descriptive Statistics}

The most common recorded reasons for culling of cows were reproductive (20\%), low production (19\%), and feet/leg and mastitis/SCC (8.5\% for both feet/leg and mastitis/SCC). Nineteen cows (11\%) were culled within $60 \mathrm{~d}$ of LDA surgery. Sixty-three cows (36\% of all surgeries) were culled within 1 yr. The distribution of cases and culling by and surgical procedure are in Table 1. Less experienced veterinarians preformed $44 \%$ $(\mathrm{n}=78)$ of the surgeries, whereas experienced veterinarians (defined as 5 or more years of clinical practice) preformed the remaining $56 \%$ of cases. There were 44 primiparous and 117 multiparous cows; 15 cows had no parity recorded. Study cows had a median parity of 3.0 and the median stage of lactation at time of surgery was 13.0 DIM; cows culled within $60 \mathrm{~d}$ of surgery had a median parity and DIM of 2.0 and 12.0, respectively. Cows culled within $1 \mathrm{yr}$ of surgery had a median lactation of 2.0 and DIM at surgery of 11.0. In all multivariable models of culling risk or time to culling, no significant difference was attributed to veterinary clinic, veterinary experience, or surgical procedure. At the time of surgery, 78 of cows had blood BHBA $\geq 1.2 \mathrm{mmol} / \mathrm{L}$.

\section{Culling Within $60 \mathrm{~d}$ of Surgery}

Of the cows that received surgical correction of LDA, $11 \%$ ( $\mathrm{n}=19$ cases $)$ were culled within $60 \mathrm{~d}$ following surgery; of these, $37 \%$ (7 of 19 cases) had dystocia at the calving immediately before diagnosis. Of the cows with LDA that were not culled within $60 \mathrm{~d}$ of surgery ( $\mathrm{n}=157$ cases), only $8 \%$ had experienced dystocia. Among cows with ketosis at the time of LDA, $21 \%$ were culled within $60 \mathrm{~d}$, whereas $26 \%$ of nonketotic cows were culled within $60 \mathrm{~d}$. Based on the final multivariable logistic regression model for culling within $60 \mathrm{~d}$ following corrective surgery, cows that had dystocia or were not ketotic $(\mathrm{BHBA}<1.2 \mathrm{mmol} / \mathrm{L})$ at the time of

Table 1. Descriptive statistics of surgical procedure and outcome for 176 cows with left displaced abomasum that underwent correction ${ }^{1}$

\begin{tabular}{|c|c|c|c|c|c|c|c|}
\hline \multirow[b]{2}{*}{ Clinic } & \multirow{2}{*}{$\begin{array}{c}\text { No. } \\
\text { of vets }\end{array}$} & \multicolumn{3}{|c|}{ Number of surgeries per technique ${ }^{2}$} & \multirow[b]{2}{*}{ Total cases } & \multicolumn{2}{|c|}{ Frequency of cases } \\
\hline & & $\mathrm{LF}$ & $\mathrm{P}$ & $\mathrm{RF}$ & & Culled $\leq 60 \mathrm{~d}$ & Culled $\leq 1$ yr \\
\hline $\mathrm{A}$ & 7 & 3 & 60 & 0 & $63(36 \%)$ & $7(37 \%)$ & $22(35 \%)$ \\
\hline B & 5 & 1 & 0 & 30 & $31(18 \%)$ & $3(16 \%)$ & $12(19 \%)$ \\
\hline $\mathrm{C}$ & 4 & 0 & 8 & 7 & $15(8 \%)$ & $3(16 \%)$ & $6(10 \%)$ \\
\hline $\mathrm{D}$ & 8 & 0 & 0 & 67 & $67(38 \%)$ & $6(31 \%)$ & $23(36 \%)$ \\
\hline Total & 24 & $4(2.3 \%)$ & $68(38.6 \%)$ & $97(59.1 \%)$ & $176(100 \%)$ & $19(11 \%)$ & $63(36 \%)$ \\
\hline
\end{tabular}

${ }^{1}$ There was no difference among veterinary clinics or surgical techniques in survival in the herd in any of the statistical models.

${ }^{2} \mathrm{LF}=$ left paralumbar fossa abomasopexy; $\mathrm{P}=$ right paramedian abomasopexy; $\mathrm{RF}=$ right paralumbar fossa omentopexy. 
Table 2. Final multivariable mixed logistic regression model for culling within $60 \mathrm{~d}$ following left displaced abomasum surgical correction for 176 Holsteins cows, controlling for veterinary clinic as a random effect

\begin{tabular}{|c|c|c|c|c|c|}
\hline \multirow[b]{2}{*}{ Item } & \multicolumn{5}{|c|}{ Culled $\leq 60$ d $(\mathrm{n}=19)$} \\
\hline & $\beta^{1}$ & $\mathrm{SE}$ & $\begin{array}{l}\text { Odds } \\
\text { ratio }\end{array}$ & $\begin{array}{c}95 \% \\
\text { CI }\end{array}$ & $P$-value \\
\hline \multicolumn{6}{|l|}{ Dystocia } \\
\hline No & $\operatorname{Ref}^{2}$ & - & - & - & - \\
\hline Yes & 2.60 & 0.34 & 13.0 & $7-26$ & $<0.0001$ \\
\hline \multicolumn{6}{|l|}{ BHBA } \\
\hline$<1.2 \mathrm{mmol} / \mathrm{L}$ & 1.10 & 0.55 & 3.0 & $1.03-9$ & 0.04 \\
\hline$\geq 1.2 \mathrm{mmol} / \mathrm{L}$ & Ref & - & - & - & - \\
\hline
\end{tabular}

LDA diagnosis had 13 (95\% CI: 7 to $26, P<0.0001)$ and 3 (95\% CI: 1.03 to $9, P=0.04)$ times greater odds of being culled within $60 \mathrm{~d}$ than cows with an easy calving or that were ketotic, respectively (Table 2).

\section{Culling Within 1 yr of Surgery}

Thirty-six percent ( $\mathrm{n}=63$ cases) of cows were culled within 1 yr of their LDA corrective surgery. The final mixed logistic regression model revealed that cows with higher serum BHBA, NEFA, and $\mathrm{Mg}$ concentration at LDA surgery had decreased odds of being culled within 1 yr (Table 3). As blood BHBA levels increased by 1 $\mathrm{mmol} / \mathrm{L}$, the odds of culling within $1 \mathrm{yr}$ were 0.95 times greater. Similarly, 1 unit increases in the concentrations of NEFA and $\mathrm{Mg}$ were associated 20 and $50 \%$ relative reductions in the odds of culling, respectively. For clinical application, given the availability of point-of-care measurement of BHBA, the predicted probability of remaining in the herd for $1 \mathrm{yr}$ following surgery was determined using the median $\mathrm{Mg}(0.8 \mathrm{mmol} / \mathrm{L})$ and NEFA $(1.4 \mathrm{mmol} / \mathrm{L})$ concentrations of the cows in the study and varying the BHBA concentrations at diagnosis (Figure 1). Cows with lower blood BHBA were less likely to remain in the herd than cows that had a higher blood BHBA level at the time of diagnosis.

\section{Survival Analysis for the Lactation Following Surgery}

The M24 rank was used as a measure of milk yield because this expresses individual first DHIA test-day yield relative to contemporary cows in the same herd. The M24 rank is a percentile rank within the herd such that the lower the number, the higher the rank in the herd and the more milk produced (i.e., an M24 rank of 10 was ranked higher and had greater test-day milk production than a cow with an M24 rank of 50). Therefore, as percentile rank increases this reflects a decreased level of milk production, which was associated with increased risk of culling. This also controls for variability between herds, as a cow producing 30 $\mathrm{L} / \mathrm{d}$ in 1 herd may be the best cow but would be an average producer in another herd. Controlling for milk production, higher serum concentrations of BHBA and Mg were protective against culling (Table 4). Dystocia, twinning, and respiratory rate at LDA surgery were also negatively associated with time to culling in univariable analyses but were not significant in the final model once controlling for milk production. For clinical application, Figures 2 and 3 illustrate that cows that had blood BHBA $<1.2 \mathrm{mmol} / \mathrm{L}$ or serum $\mathrm{Mg}<0.8$ $\mathrm{mmol} / \mathrm{L}$ at LDA diagnosis were less likely to remain in the milking herd for the remainder of the lactation.

\section{DISCUSSION}

There was no association between surgical procedure, veterinary clinic, or veterinary experience and longevity in the herd (to $60 \mathrm{~d}$ or $1 \mathrm{yr}$ following surgery). The median survival time was $566 \mathrm{~d}$ (18.9 mo), which is similar to Geishauser et al. (1998), who reported a median survival of $545 \mathrm{~d}$ following LDA surgery. Perhaps counterintuitively, given that ketosis is a risk factor for LDA (LeBlanc et al., 2005) and for culling (Roberts et al., 2012), serum BHBA levels were positively associated with longevity in the herd. Our study found that cows that were ketotic at the time of surgical correction were found to have higher longevity in the herd than those cows that were not ketotic.

In the general population, about $30 \%$ of culls occur in the first $60 \mathrm{~d}$ of lactation, the next most common period of culling is after 300 DIM (Murray, 2011). This is higher than what was seen in our study population, as only $19 \%$ of LDA surgery cows were culled within 60 d. Croushore et al. (2013) reported that $16 \%$ of culls occur in the first $30 \mathrm{~d}$, which is similar to our findings. The reason for the lower cull rate in LDA cows is not known. The overall cull rate in recent literature tends

Table 3. Final multivariable mixed logistic regression model for culling within 1 year following left displaced abomasum surgical correction for 176 Holsteins cows, controlling for clinic as a random effect

\begin{tabular}{lrcccc}
\hline & \multicolumn{5}{c}{ Culled $\leq 1 \mathrm{yr}(\mathrm{n}=63)$} \\
\cline { 2 - 6 } Item & $\beta^{1}$ & $\mathrm{SE}$ & $\begin{array}{l}\text { Odds } \\
\text { ratio }\end{array}$ & $\begin{array}{c}95 \% \\
\mathrm{CI}\end{array}$ & $P$-value \\
\hline BHBA & -0.05 & 0.03 & 0.95 & $0.92-0.98$ & 0.04 \\
NEFA & -0.21 & 0.08 & 0.81 & $0.75-0.88$ & 0.01 \\
Mg & -0.72 & 0.33 & 0.49 & $0.35-0.68$ & 0.03 \\
Intercept & 1.48 & 0.31 & 4.39 & $3.22-5.99$ & 0.03 \\
\hline
\end{tabular}


Table 4. Final multivariable Cox Proportional Hazard model for survival in the herd following left displaced abomasum surgical correction for 176 Holsteins cows, controlling for clinic as a random effect

\begin{tabular}{lrcccc}
\hline & \multicolumn{5}{c}{ Survival analysis (1 lactation) } \\
\cline { 2 - 6 } Item & $\beta^{1}$ & $\mathrm{SE}$ & $P$-value & $\begin{array}{c}\text { Hazard } \\
\text { ratio }\end{array}$ & $95 \%$ CI \\
\hline BHBA & -0.27 & 0.11 & 0.014 & 0.77 & $0.62-0.95$ \\
Mg & -2.51 & 1.27 & 0.048 & 0.08 & $0.01-0.98$ \\
Rank M24 & 0.01 & 0.006 & 0.045 & 1.01 & $1.00-1.02$ \\
\hline
\end{tabular}

${ }^{1} \beta=0.80$.

${ }^{2}$ Rank M24 is the percentile rank of the 24-h milk yield of the cow within the herd on her first CanWest DHI test following her left displaced abomasum corrective surgery.

to be above 30\%. Bascom and Young (1998) reported a cull rate of $34 \%$, and Hadley et al. (2006) had a cull rate of $31.6 \%$. This annual cull rate is lower than the 1 -yr cull rate for LDA cows $(36 \%)$.

In the present study, the odds of culling within $60 \mathrm{~d}$ of surgery were 13 times greater in cows with dystocia which later developed an LDA compared with cows without a difficult calving. Interestingly, Lyons et al. (2014) found that cows that had an assisted calving tended to be more likely to develop LDA, but that there were no differences in culling between the cows with LDA their paired controls. The increased odds of culling for nonketotic cows is supported by Croushore et al. (2013), which indicated that cows with blood BHBA $<1.2 \mathrm{mmol} / \mathrm{L}$ at the time of LDA corrective surgery were 2.5 times more likely to be removed from the herd within $30 \mathrm{~d}$ compared with cows with blood BHBA levels $\geq 1.2 \mathrm{mmol} / \mathrm{L}$, similar to our results. Croushore et al. (2013) hypothesized that this may be due to the decreased ability of the nonketotic cows to return to normal milk production. High milk yield in early lactation requires mobilization of body fat; accordingly, some level of ketonemia reflects physiologic adaptation to support lactation. Therefore, low BHBA in a subpopulation of cows (those with LDA) that are expected to have a higher-than-average prevalence of hyperketonemia may reflect poor adaptation to support (return to) an economically viable level of milk yield in the short term.

In an attempt to control for confounding of metabolic indicators in the survival analysis, milk production (M24 rank) data were forced into the model. It has been well established that the top 3 reasons for culling are milk production, reproduction, and mastitis or SCC (Bascom and Young, 1998; Hadley et al., 2006; CanWest DHI, 2014). Reproductive status was not controlled for in the present analysis because direct pregnancy data were available in the DHIA database for $<60 \%$ of the study cows. Survival in the herd is

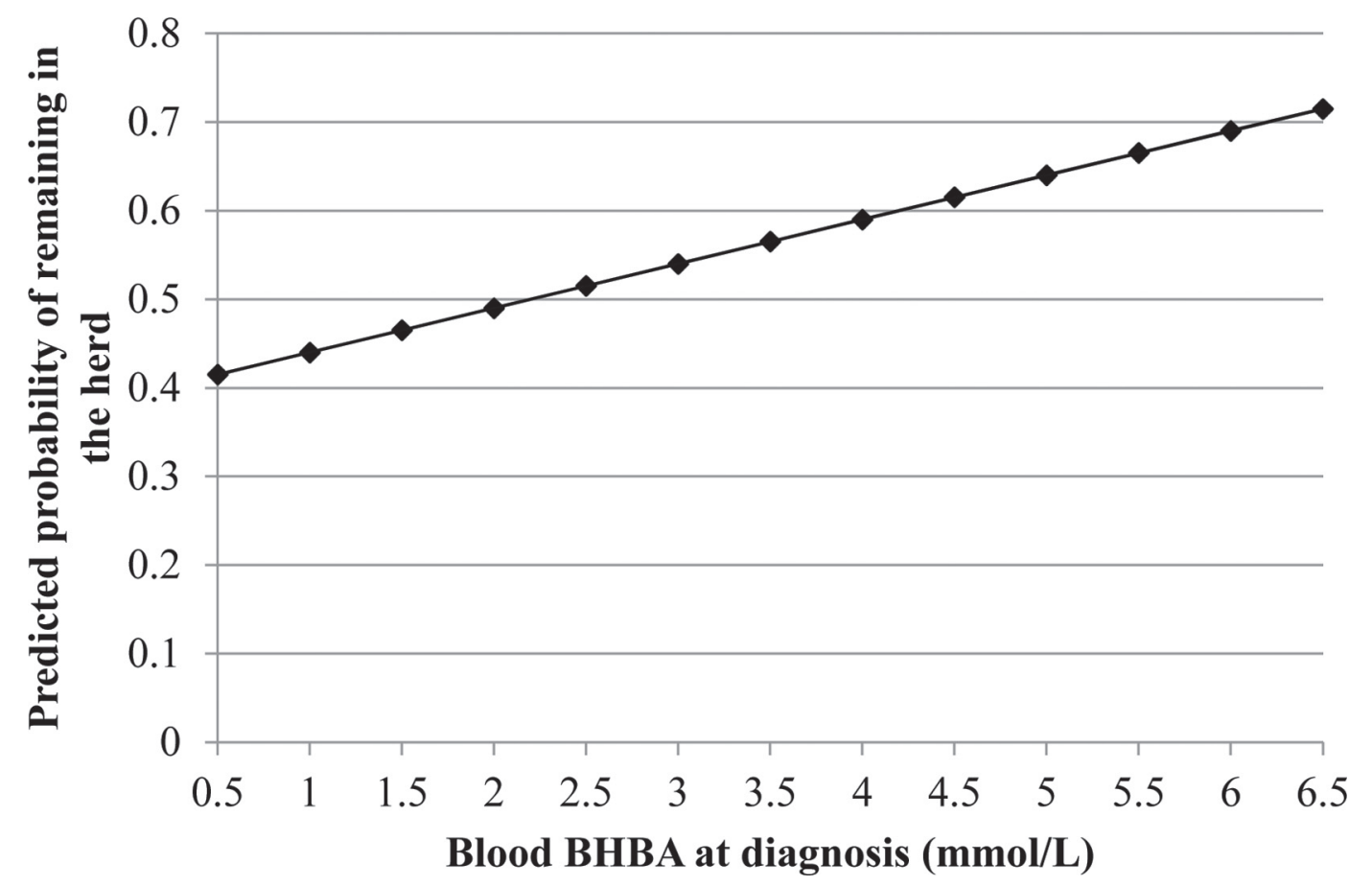

Figure 1. The predicted probability of a cow remaining in the milking herd for $1 \mathrm{yr}$ following left displaced abomasum corrective surgery based on blood BHBA at the time of diagnosis. The probabilities assume that the covariates serum magnesium and NEFA were at the median value for all study cows $(0.8$ and $1.4 \mathrm{mmol} / \mathrm{L}$, respectively). 


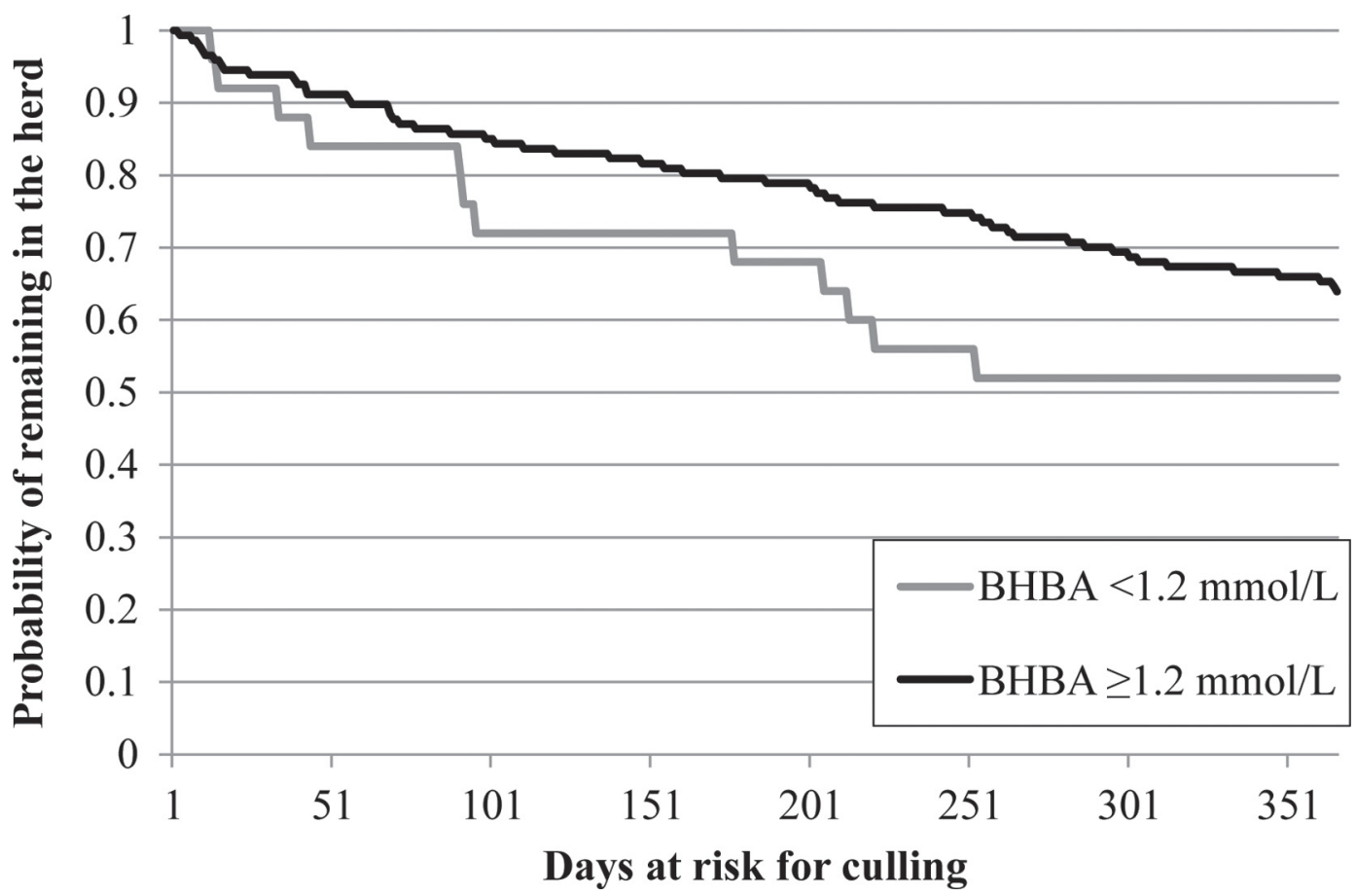

Figure 2. Univariable survival curve for the remainder of lactation based on blood BHBA levels at the time of left displaced abomasum (LDA) diagnosis, using a cut-point of $1.2 \mathrm{mmol} / \mathrm{L}$. Day 0 is defined as the day of LDA correction.

influenced by reproductive status and therefore the cow's subsequent calving date was used as an end point if available.
In the 1-yr culling model as well as the survival analysis, higher serum $\mathrm{Mg}$ was significantly associated with remaining in the herd. Magnesium is critically

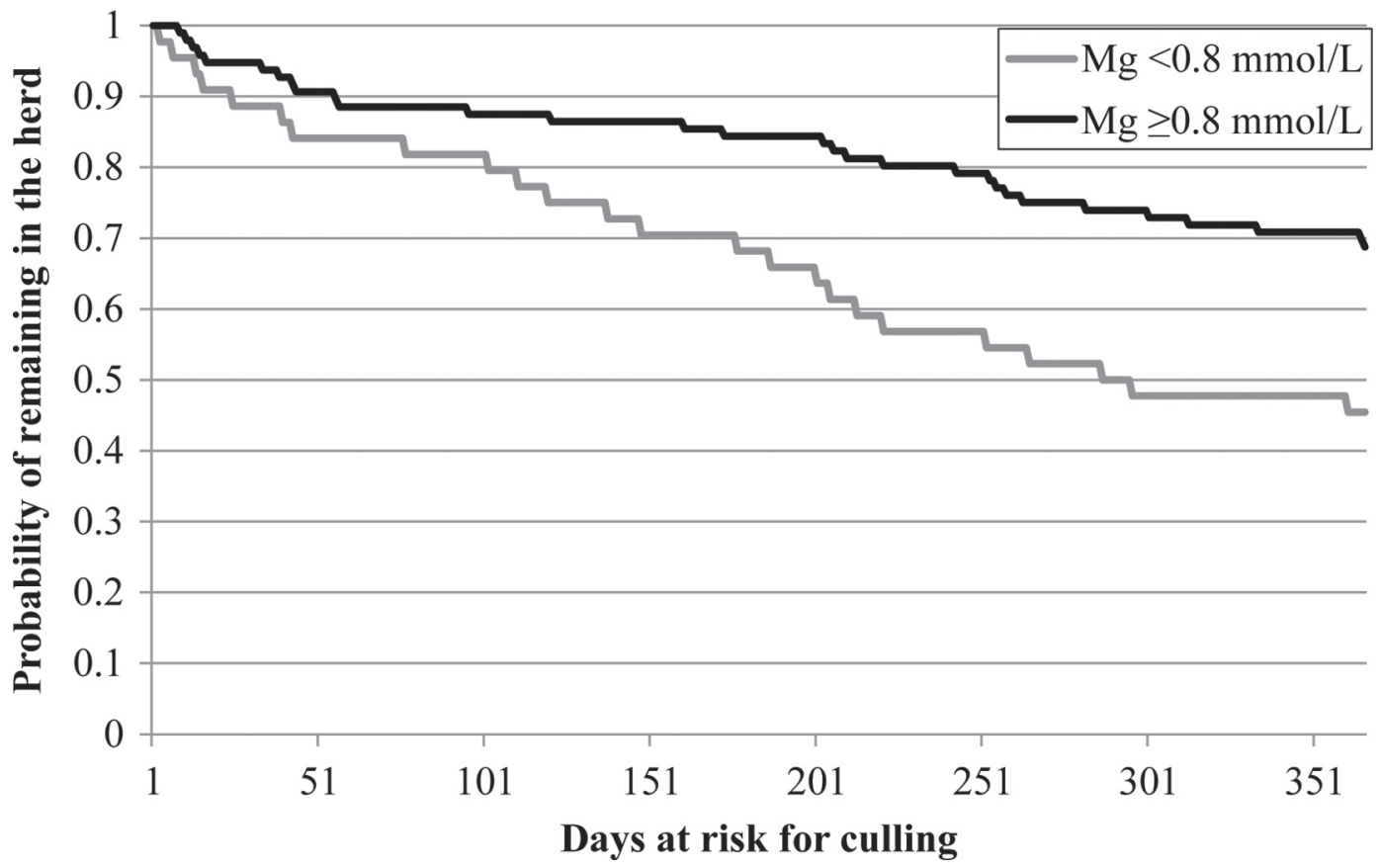

Figure 3. Univariable survival curve for the remainder of lactation based on serum $\mathrm{Mg}$ levels at the time of left displaced abomasum (LDA) diagnosis, using a cut-point of $0.8 \mathrm{mmol} / \mathrm{L}$. Day 0 is defined as the day of LDA correction. 
important in several metabolic pathways, and acts as a cofactor to many enzymes (NRC, 2001). Magnesium is involved in nerve conduction, muscle function and bone formation (NRC, 2001). In a healthy lactating dairy cow, plasma levels are normally between 0.75 and 1.0 $\mathrm{mmol} / \mathrm{L}$ (NRC, 2001). Kalaitzakis et al. (2010) found that cows with decreased magnesium and calcium levels were at an increased risk of dying or being culled. Whereas most cows had serum Mg concentrations within the reference range, a decline within that range may be meaningful. However, we had only 1 measurement of $\mathrm{Mg}$ taken at the time of LDA surgery. Neither Ca or $\mathrm{K}$ levels were predictors of culling; therefore, it seems unlikely that hypocalcemia influences culling following LDA corrective surgery.

The presence of lower BHBA as a as a risk factor in all 3 culling models (with $\mathrm{Mg}$ and NEFA in the 1 -yr culling risk model and $\mathrm{Mg}$ in the survival analysis) led us to develop a hypothesis that a subset of cows exists in which the common and repeatedly observed association of ketosis as a risk factor for LDA and other undesirable outcomes is not operant. This minority of cows with LDA but without concurrent ketosis likely were not caused by failure of adaptation to negative energy balance but rather by separate problems, such as an abomasal ulcer, lameness, or injury, which may be the initial causal factor that was not alleviated by correction of the LDA. Therefore, these cows never properly recovered even after surgical correction and were often culled. This may also be the case for those cows with lower levels of $\mathrm{Mg}$; however, we are unsure why hypermagnesemia is associated with favorable prognosis. Overall, our hypothesis for why hyperketonemia is associated with favorable prognosis is that these cows are likely higher producing around the time of surgery; therefore, following surgical correction could reach their full milking potential, whereas the lower-producing, likely not ketotic cows were culled for productivity. Croushore et al. (2013) proposed the same hypothesis for similar findings.

The present study has several limitations that should be addressed. First, the sample is a convenience sample from southwestern Ontario, and therefore, due to differences in management practices, the results may not be applicable to dairies in other areas. Lack of complete data on insemination and pregnancy also affects this research, as it resulted in the inability to control for reproductive status as a potential confounding factor in the survival analysis. It would have been ideal to collect blood samples and other data from healthy cows with similar parity and DIM status at the time of enrollment for an LDA cow to compare culling risks between cows with and without LDA.
Future studies should collect BCS, as BCS is a risk factor for both ketosis and LDA and may provide some insight into the association of nonketotic status with culling. Other potential areas to pursue would be to investigate the development of a cow-side NEFA or Mg test to make these results more applicable to practitioners and producers.

\section{CONCLUSIONS}

Dystocia before LDA and blood BHBA $<1.2 \mathrm{mmol} / \mathrm{L}$ at the time of LDA diagnosis were significantly associated with increased odds of culling within $60 \mathrm{~d}$ of surgery. Higher serum levels of BHBA, NEFA, and Mg at the time of LDA diagnosis were all positively associated with longevity in the herd. Time-to-culling analysis also indicated that higher $\mathrm{Mg}$ and BHBA were protective against culling. We recommend that veterinary practitioners and producers include consideration of the cow's history (i.e., dystocia) and blood BHBA concentration as part of the process of deciding whether to perform surgical correction of LDA, or consider prompt culling or humane euthanasia in a minority of cases.

\section{ACKNOWLEDGMENTS}

The authors thank all the participating veterinary clinics and herds, as well as the summer students involved in the initial data collection. Thanks also to Karen Hand of Strategic Solutions for helping with data acquisition. Funding for the initial research was graciously provided by Merial Canada Ltd. (Baie d'Urfe, QC, Canada) and Ontario Ministry of Agriculture, Food and Rural Affairs (Guelph, ON, Canada).

\section{REFERENCES}

Bascom, S. S., and A. J. Young. 1998. A summary of the reasons why farmers cull cows. J. Dairy Sci. 81:2299-2305.

Boulay, G., D. Francoz, E. Doré, S. Dufour, M. Veillette, M. Badillo, A. M. Bélanger, and S. Buczinski. 2014. Preoperative cow-side lactatemia measurement predicts negative outcome in Holstein dairy cattle with right abomasal disorders. J. Dairy Sci. 97:212-221.

CanWest DHI. 2014. Ontario 2013 herd management benchmarks. Accessed Mar. 1, 2014. www.canwestdhi.com/publications.htm.

Chapinal, N., M. Carson, T. F. Duffield, M. Capel, S. Godden, M. Overton, J. E. P. Santos, and S. J. LeBlanc. 2011. The association of serum metabolites with clinical disease during the transition period. J. Dairy Sci. 94:4897-4903.

Croushore, W. S. Jr., P. A. Ospina, D. C. Welch, D. J. Zawisza, and D. V. Nydam. 2013. Association between $\beta$-hydroxybutyrate concentration at surgery for correction of left-displaced abomasum in dairy cows and removal from the herd after surgery. J. Am. Vet. Med. Assoc. 243:1329-1333.

Figueiredo, M. D., D. V. Nydam, G. A. Perkins, H. M. Mitchell, and T. J. Divers. 2006. Prognostic value of plasma L-lactate concentration measured cow-side with a portable clinical analyzer in Holstein dairy cattle with abomasal disorders. J. Vet. Intern. Med. 20:1463-1470. 
Geishauser, T., M. Shoukri, D. Kelton, and K. Leslie. 1998. Analysis of survivorship after displaced abomasum is diagnosed in dairy cows. J. Dairy Sci. 81:2346-2353.

Gröhn, Y. T., S. W. Eicker, V. Ducrocq, and J. A. Hertl. 1998. Effect of diseases on the culling of Holstein dairy cows in New York State. J. Dairy Sci. 81:966-978.

Hadley, G. L., C. A. Wolf, and S. B. Harsh. 2006. Dairy cattle culling patterns, explanations and implications. J. Dairy Sci. 89:22862296.

Kalaitzakis, E., N. Panousis, N. Roubies, E. Kaldrymidou, and H. Karatzias. 2010. Macromineral status of dairy cows with concurrent left abomasal displacement and fatty liver. N. Z. Vet. J. 58:307-311.

Kalaitzakis, E., N. Roubies, N. Panousis, K. Pourliotis, E. Kaldrymidou, and H. Karatzais. 2006. Evaluation of ornithine carbamoyl transferase and other serum and liver-derived analytes in diagnosis of fatty liver and postsurgical outcome of left-displaced abomasum in dairy cows. J. Am. Vet. Med. Assoc. 229:1463-1471.

Kelton, D. F., K. D. Lissemore, and R. E. Martin. 1998. Recommendations for recoding and calculating the incidence of selected clinical diseases of dairy cattle. J. Dairy Sci. 81:2502-2509.

LeBlanc, S. J., K. E. Leslie, and T. F. Duffield. 2005. Metabolic predictors of displaced abomasum in dairy cattle. J. Dairy Sci. $88: 159-170$

Lyons, N. A., J. S. Cooke, S. Wilson, S. C. van Winden, P. J. Gordon, and D. C. Wathes. 2014. Relationships between metabolite and IGF1 concentrations with fertility and production outcomes following left abomasal displacement. Vet. Rec. 174:657. http:// dx.doi.org/10.1136/vr.102119.

Maden, M., A. S. Ozturk, A. Bulbul, G. E. Avci, and E. Yazar. 2012. Acute-phase proteins, oxidative stress, and enzyme activities of blood serum and peritoneal fluid in cattle with abomasal displacement. J. Vet. Intern. Med. 26:1470-1475.

Murray, B. 2011. Finding the tools to achieve longevity in our dairy cows. Pages 4-10 in Proceedings of the South Western Ontario Dairy Symposium, Woodstock, Ontario. http://www. dairysymposium.com/proceedings2011.php.

NRC. 2001. Nutrient Requirements of Dairy Cattle. 7th rev. ed. Natl. Acad. Press, Washington, DC.

Newby, N. C., D. L. Pearl, S. J. LeBlanc, K. E. Leslie, M. A. G. von Keyserlingk, and T. F. Duffield. 2013. The effect of administering ketoprofen on the physiology and behavior of dairy cows following surgery to correct a left displaced abomasum. J. Dairy Sci. 96:1511-1520.

Roberts, T., N. Chapinal, S. J. LeBlanc, D. F. Kelton, J. Dubuc, and T. F. Duffield. 2012. Metabolic parameters in transition cows as indicators for early-lactation culling risk. J. Dairy Sci. 95:30573063 .

Rohn, M., B. A. Tenhagen, and W. Hofmann. 2004. Survival of dairy cows after surgery to correct abomasal displacement: 2. Association of clinical and laboratory parameters with survival in cows with left abomasal displacement. J. Vet. Med. A Physiol. Pathol. Clin. Med. 51:300-305.

Shaver, R. D. 1997. Nutritional risk factors in the etiology of left displaced abomasum in dairy cows: A review. J. Dairy Sci. 80:24492453.

Stengärde, L., K. Holtenius, M. Tråvén, J. Hultgren, R. Niskanen, and U. Emanuelson. 2010. Blood profiles in dairy cows with displaced abomasum. J. Dairy Sci. 93:4691-4699.

Suthar, V. S., J. Canelas-Raposo, A. Deniz, and W. Heuwieser. 2013. Prevalence of subclinical ketosis and relationships with postpartum diseases in European dairy cows. J. Dairy Sci. 96:2925-2938. 